\title{
The Pragmatic Function of Theme: The Case of the Conditional Subordinates
}

\author{
Rosa Lorés Sanz \\ University of Zaragoza \\ rlores@posta.unizar.es
}

\begin{abstract}
The present paper discusses the possibility of adopting a politeness theory approach to the various problems raised by the speaker's choice of Theme. The discussion will focus on the case of the clause complexes which contain an adverbial subordinate of condition. In the present paper I argue that the ordering 'subordinate + main' is often perceived by the participants in conversation as being more polite than the reverse order 'main + subordinate'. The implications that this discussion has for an understanding of the general concept of Theme will also be discussed. Among others, Halliday, Fries and Downing's views on the issue of theme, as well as Brown and Levinson's Politeness Theory will be reviewed and adopted as theoretical standpoints.
\end{abstract}

\section{Introduction}

The extent to which Functional Systemic Linguistics and Pragmatics pursue the same or different ends is a matter of continuing debate. Several linguists (Leech, 1983; Butler, 1988a, 1988b, 1996; Siewierska, 1991) have argued that the concerns of both systemic linguists and pragmaticians are in many ways similar, i.e. to explain the ways in which speakers and hearers interact in context. However, for several reasons, they have remained apart. As Butler (1988a: 13) puts it, "the now substantial literature on pragmatics is all but ignored in the work of Halliday and most other systemic linguists; furthermore, there are few references to systemic work in publications on pragmatics." 
According to Martín Miguel (1998: 135), ${ }^{1}$ Halliday rejects the term 'pragmatics' for two main reasons:

i) porque no cree que la pragmática constituya un eslabón separado del aparato comunicativo que es el lenguaje; y ii) porque la etiqueta 'pragmática' surge en un contexto favorecido por las gramáticas formales (Butler 1990: 9), de ahí que lo que otras corrientes lingüísticas estudian bajo el paraguas de la pragmática, Halliday tiende a englobarlo bajo una semántica muy general que incluye fenómenos de naturaleza distinta.

In my opinion, we can profit from approaches such as Butler's (1988b: 85), who sees "substantial overlap between Halliday's concerns and those of pragmaticians." According to Butler (1988a: 14), the basic difference between the two approaches is one of emphasis as "systemic grammars tend to concentrate on the sociological factors influencing language, whereas pragmatics brings in the more psychological and philosophical influences, while, it could be argued, not necessarily neglecting the sociological." In Butler's view (1988b) systemic linguists can profit from pragmaticians' contributions; and, he (1996) sustains, also pragmaticians can benefit from a serious look at systemic models.

Very close to Butler's proposal and to the theoretical position adopted in the present paper is what Van Dijk calls 'Functional Discourse Analysis' (FDA). In his contribution to the volume Unity in Diversity, Van Dijk (1990: 27) defines FDA in the following terms:

[it is] a perspective which has a linguistic component, which deals with grammatical and other functional relations of textual structures and strategies, and a broader, interdisciplinary component, which analyses the functional relations between these textual structures and various structures of the 'context', such as those of cognition, interaction, and even the structures of the societal or cultural macro-level.

Van Dijk (1990: 27) refers to the first component as 'Functional Text Analysis' and to the second as 'Functional Text-Context Analysis', and FDA is used to denote the integration of both approaches. Thus, within this approach, the components are not seen as being in competition but as complementary.

In Van Dijk's view (1990: 28-29), Functional Text Analysis not only overlaps, but also has common roots and shares links with Functional Grammar. Functional Grammar is satisfactory when it comes to providing descriptions of functional relations within sentences and texts. However, it seems to lack a text-context analysis of functional relations which could explain textual structures, an analysis which can be accounted for within Van Dijk's Functional Text-Context approach.

With Van Dijk's proposal in mind, it is my intention in the present paper to argue that the choice of Theme in the conditional clause complex draws heavily on the pragmatic function transmitted, a function which should be catered for and explained at the contextual level. 


\section{About Theme}

Almost two decades ago Simon Dik (1981: 129) stated that there seemed to be a consensus in the belief that notions such as Topic vs. Comment, Theme vs. Rheme, Given vs. New, Focus vs. Presupposition can be interpreted as pragmatic functions, but that apart from this general agreement, there was considerable difference of opinion and much terminological confusion in the area of pragmatic functions. In the last 20 years several attempts have been made to clarify the picture, as the following quotations may show.

In his general study on Functional Grammar, Dik (1981: 130) defends the understanding of Theme as an element outside the predication, connected to it in virtue of its pragmatic character. In contrast, Topic and Focus are considered as constituents of the Predication proper:

A constituent with Topic function presents the entity 'about' which the Predication predicates something in the given setting. A constituent with Focus function presents the relatively most important or salient information with respect to the pragmatic information of the Speaker and the Addressee.

In fact, Dik (1981: 140) acknowledges the existing confusion between the notions of Theme and Topic when he states:

[...] what we call Theme is very often referred to as the Topic (e.g., in the usage of $\mathrm{Li}$ and Thompson 1976). We do not follow this usage, because we want to be able to distinguish the pragmatic function of Theme, which operates outside of the Predication, from the pragmatic function of Topic, which operates inside the Predication.

The concept of Topic is extensively discussed by Siewierska (1991: 151), who, in agreement with Dik, defines it as "what the utterance is primarily about or, more fully, as the entity about which the predication predicates something in a given setting", but admits that the distinction between Topic and Theme is still in need of further refinement.

Within the Systemic Functional approach, the interest has focused on the definition of the concept of Theme. Halliday (1985: 39) understands Theme as both "the point of departure of the message" and "that with which the clause is concerned", a definition which, in my opinion, reflects certain aspects of Dik's Theme and his Topic. Thus, Halliday's spatial metaphor "point of departure" can somehow be related to Dik's understanding of Theme as a constituent which precedes the Predication. Moreover, a parallel can be drawn between Halliday's definition of Theme as "that with which the clause is concerned", and Dik's Topic, a constituent which presents the entity 'about' which the Predication predicates something in the given setting. ${ }^{2}$

Halliday's definition of Theme has led to a fruitful discussion, ${ }^{3}$ and one of its more interesting conclusions has been that what Halliday refers to as "what the clause is about" equates in systemic functional grammar with what others called Topic. Thus, Downing (1991), one of the more relevant contributors to the issue, suggests a dissociation of Theme, 
in the sense of "initial element", from Topic. She considers Theme and Topic as distinct categories which may coincide in one realisation, when this realisation is a participant. Downing (1991: 127) says: "[T]heme may coincide with Topic in the same wording, just as it may coincide with Given, but they are different categories. Topic will identify what a particular part of the text is about, while Theme (or initial element) represents the point(s) of departure of the message. "4

I personally uphold Downing's (1991) view on Theme and Topic as distinct categories, the former understood as the initial constituent whose discourse function is that of a framework setting device, and the latter as 'what the message is about'. Moreover, further implications can be derived from the definition of Theme in such terms. The conceptualisation of Theme as an initial element is not a mere spatial metaphor. As a framework setting device, it also functions as the orienter of the message, the angle from which the addresser projects his/her message. As Fries (1995a: 318) puts it, "[i]t orients the listener/reader to the message that is about to be perceived and provides a framework for the interpretation of that message", or as he (1994: 234) also states, "[Theme] tells the reader how to understand the news conveyed by the clause. As a result, one should expect the choice of thematic content usually to reflect local concerns."

Theme, then, is a meaningful choice, and the fact that the choice of Theme may shape and determine the addressee's interpretation of the message is specially relevant for the case I am going to discuss.

\section{Clauses as themes: from a textual to an interpersonal function}

For the purpose of the discussion that I am about to present, I shall carry out a brief review of what has been said so far about clauses as Themes. First Halliday (1985) and then Downing and Locke (1992) among others discuss the possibility of having a clause as Theme, within the so called 'clause complex'.

Halliday (1985: 57) openly states his intention of discussing only one type of complex structure, that of Head (dominant) clause plus Modifying (dependent) clauses (Hypotaxis). He considers the typical sequence as that of 'Head + Modifying', but, he admits, the reverse is also possible, with the Modifying clause preceding; and where that order is used, "the motive is thematic." Halliday (1985: 57) discusses the clause complex "Give that teapot away if you don't like it", which follows, in his opinion, the typical order of 'Head + Modifying'. In his view, the clause which contemplates a reverse order, "If you don't like that teapot, give it away", has the effect of thematizing "your imputed dislike of the teapot."

In his own view these examples pose no great problems of analysis, but, as we shall see below, the question we posit here is not which constituent becomes Theme on each occasion, but the motivations behind the choice of one clause or another as Theme.

When discussing the use of clauses as Themes, Downing and Locke (1992: 234) deal with Themes in coordinated clauses (Parataxis), which, in their view, "typically reflect the chronological order of the events described." They understand Theme as the natural, 
temporal and factual starting point of the sequence. When there are no chronological criteria to be taken into account, Downing and Locke (1992: 235) understand that the choice of Theme is still important "since it allows what the speaker considers to be the most important information, within the current context, to be placed towards the end of the sentence."

As far as hypotactically related clauses are concerned, Downing and Locke (1992: 235) admit that 'main + subordinate' ('Head' and 'Modifying' in Hallidayan terms) has been suggested as the unmarked order, but that the reverse is also possible, and they point out that the tendency to place new and important information towards the end may be a determinant in the choice of the initial clause in the clause complex. They $(1992: 235)$ state:

Finite subordinate clauses express meanings of condition, concession, reason, time and degree among others. When such clauses are thematised, they provide a circumstantial framework within which the rest of the sentence develops, or until a new framework is set up [...]. If a main clause is chosen as Theme, it may be because a personal framework has been preferred.

In this respect, and in contrast with more generally accepted assumptions, Downing and Locke (1992: 235) see 'subordinate + main' as the unmarked order in the case of conditional clauses, "as they reflect iconically the logical relationship involved." Other linguists, such as Prideaux and Hogan (1993: 397), point to 'main + subordinate' as the unmarked order, basing their statement on the claims of studies by Clark and Clark (1968, 1977), Bever (1970), and Givón (1983) ${ }^{5}$, who have argued that it is not iconicity but rather syntactic clause order that indicates markedness.

In an earlier paper, Downing (1991: 135) discusses conditional initiators within what she calls "situational frameworks" ${ }^{6}$, which are defined as "those initial elements which, while being neither participants, processes, nor spatio-temporals, nevertheless set up a framework which in some way provides a point of departure for an ensuing stretch of discourse." According to Downing, conditionals present a situation in the main clause which is directly contingent on that of the conditional clause. In her view, the importance of a conditional initiator is that "it functions as a point of departure for an unreal situation or series of situations" (1991: 139). She then states that not all sentences introduced by "if" express direct conditions, and sometimes the notion of condition combines with, or is replaced by, some other contingent meaning, such as space, time, result or concession. Downing (ibid.) provides an example of if-clause which implies recurrent temporal contingency:

If any other man wandered into his visible universe he fought him, and if he could he slew him.

However, I believe that there are other meanings which can combine with the conditional meaning. These are the type of conditional meanings which accompany requests and commands. Consider the following example: 
If you have the time, give me a hand with those boxes.

The question of clause order in conditionals is also a point of discussion in Schiffrin's contribution (1992). Schiffrin uses discourse analysis to examine the relationship between topic and givenness and the relationship between topic, givenness and clause order. The problem of clause order in conditionals is centred upon a clash between two independent and equally well-motivated principles: if-clauses as topics, and the given/new information order. Schiffrin (1992: 193) concludes that, whereas preposed if-clauses always provide given information, postposed if-clauses seem to follow either principle: some are topics (although with a narrower role in discourse than preposed if-clauses) and some are new information. $^{7}$

Another contributor to the issue of thematic identification of clause complexes is Fries (1994, 1995a, 1995b), who finds it useful, when working on Theme, to deal with a unit slightly larger than the clause, which he (1995b: 49) calls an "independent conjoinable clause" (or clause complex). It consists of an independent clause together with all hypotactically related clauses and words that are dependent on that independent clause. When analysing the Theme of clause complexes, Fries (1995b), following Halliday, distinguishes between the thematic identification of 'subordinate + main' and that of 'main + subordinate'. The Theme of the former sequence is the whole subordinate clause. The Theme of the latter is the first topical element of the main sentence. He (1995b:49) provides the following example:

If John comes, we will too.

We will come, if John comes

Although Fries' intention in dealing with the issue of Themes in clause complexes is to demonstrate that the information thematised relates strongly to the perceived flow of information of the text, once again he makes thought-provoking and relevant observations for our case. Fries (1995b: 58) sees the use of thematic information as regulated by a set of principles, of which the general overriding one is: "The Theme of a clause complex provides a framework within which the Rheme of the clause complex can be interpreted."

I find particularly interesting the implications we can derive from this general principle, which can be summarised in the following quotation (Fries 1995a: 319):

If Theme is a meaningful element on the level of clause or clause complex, then we should find that the kinds of meanings that are made thematic would vary depending on the purposes of the writers. Further, we should be able to manipulate reader's and listener's reactions to texts by changing the content of the themes of those texts in much the same way that we can manipulate reader and listener reactions to texts by changing the words of the text.

Dealing specifically with the clause complex Fries (1995b: 55) says: 
$[\ldots]$ one can manipulate people's reactions to texts by controlling the information which is placed thematically within the clause complexes of these texts. That is, thematic status is significant. Authors and speakers [...] use initial position in clause complexes to communicate something Halliday has called the peg on which the message is hung.

There are then two basic ideas underlying these statements which constitute the basis for my discussion: (i) the fact that thematic choice is meaningful, and (ii) the fact that by choosing the information which is to appear in thematic position, the addresser is trying to control the addressee's reaction to the text. If we understand interpersonal meaning as "enacting social relationships", and textual meaning as "creating relevance to context" (Halliday 1985: 36), we should, therefore, bear in mind, that thematic structure does not only fulfil a textual function, but also performs an interpersonal function.

The fact that Theme fulfils a double, textual and interpersonal, function seems to be confirmed by some linguists who sustain what Berry (1996: 30-31) calls "the overlapping hypothesis", proposed by Matthiesen and Ravelli (1992). ${ }^{8}$ The basic idea is that the thematic portion of a clause carries the main weight of the interpersonal and textual meaning, while the rhematic portion of the clause carries the main weight of the ideational meaning. Berry (1996: 53) wonders how meanings can be interpersonal and textual at the same time, since they are usually regarded in Systemic-Functional Linguistics as distinct. She quotes Halliday's (1978: 145) emphasis that textual categories are second order categories, that textual meaning has the 'enabling' function with regard to the other types of meaning. Theme, according to Berry (1996: 60), is the location for priority meanings of the types that are communicatively important: meanings that have to do with establishing tone of voice, social relations, type of interactions (i.e., interpersonal meanings); and meanings of different parts of a text (i.e., logical meanings).

Also close to my stance is Lotfipour-Saedi and Rezal-Tajani's (1996) position in their study of the relationship between the thematic arrangements across different genres (advertisements, journalistic articles, scientific and literary texts). The authors (1996: 240) point to the existence of a 'noticeable strategy' which they call 'mitigating strategy' (following Leech 1983), and which occurs "where the relative order of topical and nontopical theme-position elements versus non-theme-position elements is motivated by the discourse producer's inclination to mitigate the force associated with sending a specific and often unpleasant message." Lotfipour-Saedi and Rezal-Tajani (1996: 24) give an example of the use of a marked prepositional phrase as Theme designed to reduce the force associated with the receiver or beneficiary of an unpleasant action:

In water polo, the team of our country was defeated.

The authors explain that, semantically, and in comparison with the unmarked nominal group functioning as subject ("the team of our country"), the function of the marked prepositional phrase (i.e. "in water polo") is to restrict the defeat of the team of the country to "water polo." 
Another hint at the interpersonal function of Theme is found in Bowers' (1988) study of thematisation in legal English. Bowers centred his research on Bentham, a 19th century drafter of codes, who emphasised the need to gain the reader's attention when it came to selecting what we now identify as Theme. Bowers (1988: 94) concludes that "the intention and effect of thematization are to make interpretation easier for the reader by having the sentence structure mimic the order of attention."

Thus, Theme, as the orienter of the message, seems to take account of a series of sociopragmatic factors, such as the specific audience to which the text is addressed, the social variables of power and distance by which they are related, the social setting in which the text is produced, the communicative purpose of the text itself, etc. I believe that these factors, all of them meaningful from the interpersonal/pragmatic point of view, constitute an explanatory device for those instances in which a textual analysis fails to give a convincing explanation for the choice of Theme. In my view, this is the case of those clause complexes which are formed of an adverbial subordinate of condition and a main clause which expresses a request or command.

The concept of markedness seems to have something to do with those occasions on which the interpersonal meaning not only works together with, but may overrate the textual meaning of Themes. But, what do we understand by 'marked theme'? In general terms, markedness claims that there is an alternative to a prototypical, more frequent unmarked form. And, as Prideaux and Hogan (1993: 398) state, the question immediately arises as to "what communicative purposes are served by the markedness distinction." That is, we are not so much interested in which elements are considered marked Themes, but why and to what purpose are certain elements marked as Themes. The answer to these questions may be sought beyond the boundaries of syntax and within the field of the interpersonal function of language, which includes factors of a sociopragmatic type.

\section{The interpersonal meaning of adverbial subordinates of condition in thematic position: a case study}

So far, there are two points that I have tried to address: (i) the choice of Theme by the addresser is meaningful and, therefore, together with the textual meaning, it portrays an interpersonal/pragmatic meaning; (ii) markedness in the clause complex is not simply determined by syntactic order, it may also embody an interpersonal function.

I believe that these two premises can be tested and exemplified successfully in the case of adverbial subordinate clauses of condition which accompany requests and commands. My hypothesis is that when such subordinates are thematised, the resulting marked order 'subordinate + main' can be explained not only in terms of informative flow, but also in terms of the addresser's intention to soften the imposition that the request/command expressed in the main clause might mean for the addressee. In other words, the marked order can be explained in the light of Politeness Theory. 
The expression of linguistic politeness has been thoroughly studied by Brown and Levinson $(1978,1987)$. Their point of departure is "the extraordinary parallelism in the linguistic minutiae of the utterances with which persons choose to express themselves in quite unrelated languages and cultures" (1987: 55), and their objective is to describe and account for such parallelism by means of a contrastive study.

For their methodological framework they postulate a model person (MP), endowed with two special properties: 'rationality' and 'face' (1987: 58). 'Rationality' refers to the application of a specific way of reasoning which guarantees the ability to choose effective courses of action to achieve the intended effects (1987:64). Derived from Goffman's model (1967), 'face' is a key concept which refers to the public self-image that every person wants to claim for him/herself (1987: 61).

It is generally understood that speakers tend to cooperate (and expect cooperation from others) in maintaining face in every verbal interaction, and this cooperative attitude is based on the assumption that both the speaker's and the hearer's face can easily be threatened. Brown and Levinson $(1978,1987)$ assume that both the awareness of each other's face and the social need to avoid loss of face are universal, and they prefer to define 'face' not as an arbitrary norm, acknowledged by all members of society, but as something whose protection is a shared need and a mutual interest. They conceive 'face' as consisting of two related aspects: positive and negative, the former understood as every individual's desire that his/her self-image be appreciated and approved of, and the latter as every individual's claim to freedom of action and freedom from imposition.

Face, in its positive and negative aspects, and as the speaker's and the hearer's face, can be threatened by certain acts which Brown and Levinson call Face Threatening Acts (FTAs), whose impact can be reduced by the use of certain politeness strategies. ${ }^{9}$ In order to choose an appropriate politeness strategy to counteract the threat involved in an FTA, any model person has first to assess the danger that the realisation of the FTA implies ${ }^{10}$, such assessment being calculated on the basis of three sociological variables: the social distance (D) between the speaker (S) and the hearer $(\mathrm{H})$, the relative power $(\mathrm{P})$ of $\mathrm{S}$ and $\mathrm{H}$, and the absolute ranking of the imposition (R) in the given culture. The results of that calculation will guide the speaker in the selection of the most appropriate strategy to use in a given situation (1987: 67-70). The following strategies are available: bald-on-record, positive politeness, negative politeness, off record, and non-performance of the FTA.

Brown and Levinson (1987: 93) account for the relationship between the ordering of elements and the expression of politeness, as the following passage shows:

It appears that selection of a set of strategic wants to be realised by linguistic means may also involve the organisation and ordering of the expression of these wants, so that (1) may be more polite than (2):

(1) If you don't mind me asking, where did you get that dress?

(2) Where did you get that dress, if you don't mind me asking?

and (3) more polite than (4): 
(3) Goodness, aren't your roses beautiful! I was just coming by to borrow a cup of flour.

(4) I was just coming by to borrow a cup of flour. Goodness, aren't your roses beautiful!

The authors leave the case unexplained although they point to questions of topicalization and focus as a possible explanation.

The link between thematic structure and pragmatic factors such as politeness has already been hinted at by several linguists. Thus, within the frame of Functional Discourse Analysis, Van Dijk (1990: 40-41) states the need to go beyond the limits of the sentence and the text and to enter the domain of discourse:

[...] the discourse mapping of the information from the situation model is also a function of pragmatic and interactional conditions of the discourse, such as the goals, interests, or the mutual knowledge of the speech participants and the communicative relevance of specific elements of information or discourse (inter)action. For instance, facts or objects may be important, given, close, or recent in the situational model, but still occupy a later or less prominent position in discourse for tactical reasons, such as those of face-keeping, positive self-presentation or persuasion. ${ }^{11}$

Let us now compare the following examples:

(a) Can you give me a lift, if you are not in a hurry?

(b) If you are not in a hurry, can you give me a lift?

What are the motivations behind the choice of one or other ordering of elements? Given that Theme is the point of orientation, the angle from which we project the message (and not necessarily what the message is about), and that the element in thematic position establishes a framework within which the hearer interprets what comes next, and, moreover, that the choice of Theme by the speaker is a conscious choice, since she wants her hearer to interpret the message from that angle, then we cannot conclude that the difference between (a) and (b) is merely structural, logical or syntactic. In my opinion, and given the condition expressed above (that the main clause expresses an imposition on the hearer), the thematisation of the conditional clause implies an attempt on the part of the speaker to mitigate the imposition that the request imposes on the hearer. That is, (b) is meant to be interpreted by the hearer as 'more polite' than (a): in (a) the point of orientation is set by the imposition itself, whereas in (b) the condition, which functions as a mitigating device, is the point from which the hearer interprets the message.

We could further argue that the reason why (b) is interpreted as more polite than (a) can be searched in the textual arrangement of elements. Let us remember here what Schiffrin's conclusions (1992) were as regards the position of the if-clause. She sustained that whereas preposed if-clauses always provide given information, and, in this sense, fulfil both the principle of if-clauses as topics and the given/new information order principle, postponed if-clauses may follow either principles: as topic or as new information. This conclusion is 
in tune with the pragmatic motivation which is behind the information order given/new. Schiffrin (1992: 179) says:

The given/new order suggests that speaker/hearer cooperation is critical to the process of conveying information and, thus, that cooperation plays a central role in language production and interpretation. [...] the given/new order eases the transmission of information to a recipient because it places information assumed to be new in a context of information assumed to be familiar.

In other words, if the addresser is taking some trouble to make things easier for the addressee, is she not being more polite (or cooperative) when adhering to the principle of given/new order?

Although only a well-informed empirical project could eventually demonstrate what is being sustained here, I carried out a test on 20 native English speakers to whom the extracts below were shown. Passage A is an original extract from All my Sons, by Arthur Miller (1947). The passage contains four instances of the type of clause complex being analysed in this paper. Three out of those four instances are uttered by Keller, and follow the marked order 'subordinate + main'. The fourth instance, uttered by Chris, follows the unmarked order 'main + subordinate'. In passage B the clause complexes have been manipulated, with the result that Keller's clauses now follow the order 'main + subordinate', and the clause uttered by Chris the order 'subordinate + main'. The informants were not given details of the manipulation. They were only given the following context for the text: Chris is Keller's son. He has just found out that his father was selling defective spare parts to the Army during the war. As a result, several pilots were killed when the aircrafts crashed; among them, Chris's brother, Larry.

The informants were simply asked to identify which character was being 'more polite' in each passage. All the 20 informants realised what the differences between the two passages were. 18 out of 20 reported that in passage A Keller ('subordinate + main'), was being more polite than in passage $B$, whereas Chris ('main + subordinate') was being less polite in passage $A$ than in passage $B$.

Passage A

KELLER: What's the matter with you? I want to talk to you.

CHRIS: I've got nothing to say to you.

KELLER, taking his arm: I want to talk to you!

CHRIS, pulling violently away from him: Don't do that, Dad. (1) I'm going to hurt you if you do that. There's nothing to say, so say it quick.

KELLER: Exactly what's the matter? What's the matter? You got too much money? Is that what bothers you?

CHRIS, with an edge of sarcasm: It bothers me.

KELLER: (2) If you can't get used to it, then throw it away. You hear me? Take every cent and give it to charity, throw it in the sewer. Does that settle it? In the sewer, that's all. You think I'm kidding? I'm tellin' you what to do, (3) if it's dirty then burn it. It's your 
money, that's not my money. I'm a dead man, I'm an old dead man, nothing's mine. Well, taik to me! What do you want to do!

CHRIS: It's not what I want to do. It's what you want to do.

KELLER: What should I want to do? Chris is silent. Jail? You want me to go to jail? (4) If you want me to go, say so! Is that where I belong? Then tell me so.

(All my Sons, p.124)

\section{Passage B}

KELLER: What's the matter with you? I want to talk to you.

CHRIS: I've got nothing to say to you.

KELLER, taking his arm: I want to talk to you!

CHRIS, pulling violently away from him: Don't do that, Dad. (1) If you do that I'm going to hurt you. There's nothing to say, so say it quick.

KELLER: Exactly what's the matter? What's the matter? You got too much money? Is that what bothers you?

CHRIS, with an edge of sarcasm: It bothers me.

KELLER: (2) Throw it away, if you can't get used to it. You hear me? Take every cent and give it to charity, throw it in the sewer. Does that settle it? In the sewer, that's all. You think I'm kidding? I'm tellin' you what to do, (3) burn it, if it's dirty. It's your money, that's not my money. I'm a dead man, I'm an old dead man, nothing's mine. Well, talk to me! What do you want to do!

CHRIS: It's not what I want to do. It's what you want to do.

KELLER: What should I want to do? Chris is silent. Jail? You want me to go to jail? (4) Say so, if you want me to go! Is that where I belong? Then tell me so.

\section{Further implications}

In the present paper I have tried to contribute some further considerations in line with a view held by some Functionalist grammarians that postulates that the choice of Theme is never gratuitous. I based my discussion on examples of clause complexes of the conditional type, and I sustained that one explanation for the choice of Theme may be the expression of politeness. This has a series of implications for the concept of Theme. Firstly, thematic structure cannot be accounted for simply in terms of textual meaning. The choice of Theme may sometimes be motivated also by the speaker's intention to express a certain pragmatic meaning. In this respect, and as I hope I was able to show in the presentation of the case study, we need to consider both textual and pragmatic choices in conjunction, as both points of view work together towards a satisfactory explanation for the preference of a certain element as Theme. Secondly, the fact that some conditional subordinate clauses in thematic position may act as politeness devices has a series of implications with respect to the Hallidayan concept of 'multiple Theme'. Halliday (1985: 53) says: 
The Theme always includes one, and only one, experiential element. This may be preceded by elements which are textual and/or interpersonal in function; if so, these are also part of the Theme.

This statement implies that the three metafunctions, textual, interpersonal and ideational, are expressed by means of different, separate, elements. However, this would appear to be not always the case and, under certain conditions, both interpersonal and ideational meanings are expressed by means of a single element. Thus, to the Hallidayan concept of 'simple/multiple Theme', we could add the notion of the 'multi-functionality' of simple Themes.

As a general conclusion, what is being questioned here, as in many other and weightier studies, is the widely accepted assumption that the initial position in the clause has a clearcut function, and, in more general terms, Halliday's statement (1985: 35) that "different kinds of meaning tend to be realized in systematically different ways."

\section{Notes}

1. Martín Miguel (1998) analyses Systemic Functional Grammar in the light of metatheoretical parameters, in order to relate Halliday's proposal to other grammatical theories.

2. Halliday does not explicitly discuss the notion of Topic, but refers to Topical Theme, which he (1985: 54) defines as "the ideational element within the Theme functioning as Subject, Complement or circumstantial Adjunct."

See Gómez González (1997) for an interesting contrastive critique of Functional Grammar Topic and Systemic Functional Grammar Theme. In her view (1997: 81), "both the combining FG analysis of Topic and the separating SFG account of Theme are pervaded by a number of weaknesses that impede a functionally adequate characterisation of these categories in either of the two programmes."

3. See Berry (1996) for different systemic functional views on Theme.

4. According to Gómez González (1996: 124), Downing's (1991), as well as Huddleston's $(1988,1991,1992)$ objections to Halliday's definition of Theme can be overcome "provided that this category is approached from a separating perspective (see Fries 1981, 1983) and its feature of 'aboutness' is interpreted in a relational sense." Gómez González (1996: 129) believes that Halliday dissociates Theme from Topic just as Huddleston and Downing propose. Seen in this 'separating' perspective, Halliday's Topic may be considered to be a non-structural category at the level of texts; it tells us 'what texts are about' referentially, by means of non-structural relationships of presupposition, or cohesion.

5. In Prideaux and Hogan (1993: 398).

6. Downing takes the term "situational framework" from Lowe (1987: 7, in Downing 1991: 128).

7. Further functionalist studies about the position of if-clauses include Marchese (1987) and Ramsey (1987). Marchese (1987: 263) observes that, in procedural texts from Godié, a West Indian language, an unusually high number of conditional clauses occur. She claims that these clauses have an important text-organising function, breaking the discourse into significant units. 
Ramsey (1987: 385) sustains that, in written discourse, preposed if-clauses (and also whenclauses) perform different pragmatic functions than those of postposed if-clauses and whenclauses: preposed clauses are thematically associated to the preceding discourse as well as to the main clause, and thus have a broader scope. Postposed clauses are only related to their main clause, and thus have a more localized scope.

8. In Davies, M. and L. Ravelli. (eds.) (1992). Advances in Systemic Linguistics: Recent Theory and Practice. London: Pinter.

9. Brown and Levinson $(1978,1987)$ include and devise a whole, though not exhaustive, typology of FTAs, according to whether they threaten the positive/negative face of the speaker/hearer. Orders, suggestions, offers, promises, compliments, complaints, excuses, apologies, among others, may be considered FTAs.

10. Brown and Levinson make use of the term 'weight' to refer to the threat involved in an FTA.

11. My own italics.

\section{Works Cited}

Berry, Margaret (1996): "What is Theme?". In M. Berry et al, eds., Meaning and Form: Systemic Functional Interpretation. New Jersey: Ablex Publishing Company, 21-64.

Berry, Margaret, Christopher Butler, Robin Fawcett and Guowen Huang (eds.) (1996): Meaning and Form: Systemic Functional Interpretation. New Jersey: Ablex Publishing Company.

Bowers, Frederick (1988): "Thematization in legislative language: The observations of Bentham and Coode in relation to the Functional Grammar definition of Theme". In E. H. Steiner and R. Veltman, eds., Pragmatics, Discourse and Text: Some Systemically-inspired Approaches. London: Pinter Publishers, 90-98.

Brown, Penelope and Stephen C. Levinson (1978): "Universals in Language Usage: Politeness Phenomena". In E. N. Goody, ed., Questions and Politeness. Strategies in Social Interaction. Cambridge: Cambridge University Press, 56-289.

(1987): Politeness: Some Universals in Language Usage. Cambridge: Cambridge University Press.

Butler, Christopher S. (1988a): "Meeting the challenge of "pragmatics'". In E. H. Steiner and R. Veltman, eds., Pragmatics, Discourse and Text: Some Systemically-inspired Approaches. London: Pinter Publishers, 3-27.

- (1988b): "Pragmatics and Systemic Linguists". Journal of Pragmatics 12: 83-102. (1996): "On the Concept of an Interpersonal Metafunction of English". In M. Berry et al., eds., Meaning and Form: Systemic Functional Interpretation. New Jersey: Ablex Publishing Company, 151-181.

Dik, Simon C. (1981): Functional Grammar. Dordrecht and Providence: Foris Publications.

Downing, Angela (1991): "An Alternative Approach to Theme: A systemic-functional perspective". Word 42(2): 119-143.

Downing, Angela and Philip Locke (1992): A University Course in English Grammar. New York: Prentice Hall.

Fries, Peter H. (1994): "On Theme, Rheme and Discourse Goals". In M. Coulthard, ed., Advances in Written Text Analysis. London: Routledge, 229-249. 
(1995a): "Themes, Methods of Development, and Texts". In R. Hasan and P. H. Fries, eds., On Subject and Theme. A Discourse Functional Perspective. Current Issues in Linguistic Theory, 118. Amsterdam: John Benjamins, 317-359.

(1995b): "Patterns of Information in Initial Position in English". In P. H. Fries and M.

Gregory, eds., Discourse in Society: Systemic-Functional Perspectives. Vol. L. Norwood, New Jersey: Ablex Publishing Corporation, 47-66.

Gómez González, M. Ángeles (1996): "Theme: Topic or Discourse Framework?" Miscelánea 17: $123-140$.

- (1997): "A critique of topic and theme within the frameworks of Functional Grammar (FG) and Systemic-Functional Grammar (SFG)". Resla 12: 75-94.

Halliday, M. A. K. (1985): An Introduction to Functional Grammar. London: Arnold.

Leech, Geoffrey (1983): Principles of Pragmatics. London: Longman.

Lotfipour-Saedi, Kazem and Forouzan Rezai-Tajani (1996): "Exploration in thematization strategies and their discoursal values in English". Text 16(2): 225-249.

Marchese, Lynell (1987): "On the role of conditionals in Godié procedural discourse". In R. S. Tomlin, ed., 263-280.

Martín Miguel, Francisco (1998): La Gramática de Halliday desde la Filosofía de la Ciencia. Almería: Servicio de Publicaciones de la Universidad de Almería.

Miller, Arthur (1988 (1947)): All my Sons. London: Methuen.

Prideaux, Gary D. and John T. Hogan (1993) "Markedness as a discourse management device: The role of alternative adverbial clauses". Word 44(3): 397-411.

Ramsey, Violeta (1987): "The functional distribution of preposed and postposed 'if' and 'when' clauses in written discourse". In R. S. Tomlin, ed., Coherence and Grounding in Discourse. Amsterdam/Philadelphia: John Benjamins, 383-408.

Schiffrin, Deborah (1992): "Conditionals as topics in discourse". Linguistics 30: 165-197

Siewierska, Anna (1991): Functional Grammar. London: Routledge.

Steiner, Erich H. and Robert Veltman (eds.) (1988): Pragmatics, Discourse and Text: Some Systemically-inspired Approaches. London: Pinter Publishers.

Tomlin, Russell S. (ed.) (1987): Coherence and Grounding in Discourse. Amsterdam: John Benjamins.

Van Dijk, Teun A. (1990): "Issues in Functional Discourse Analysis". In H. Pinkster and I. Geene, eds., Unity in Diversity: Papers Presented to Simon C. Dik on his 50th birthday. Dordrecht and Providence: Foris Publications, 27-46. 